\title{
ART IN SCIENCE AND SCIENCE IN ART - REFLECTIONS THROUGH THE LENSE OF CITIZEN SCIENCE
}

\author{
Christine Marizzi $a *$ and Pamela Bartar $b c *$ \\ aBioBus, \\ 1361 Amsterdam Avenue, Suite 340, New York, United States of America \\ bCentre for Social Innovation (ZSI), \\ Linke Wienzeile 246, 1150 Vienna, Austria \\ c University of Applied Arts Vienna, \\ Oskar-Kokoschka -Platz 2, 1010 Vienna, Austria \\ E-mail: christine@biobus.org,bartar@zsi.at
}

The contribution follows the idea of cross-pollination between the arts and science for citizen science in the context of education and inquiry-based learning. SciArt can be understood as a hybrid of scientific and artistic expertise generating novel narratives and rather unexpected approaches. Putting the focus on science outreach aiming for public engagement and SciArt offers new ways to citizen science and other collaborative, participatory or action-based forms of research.

Citizen science projects at the intersection of SciArt often aim to educate their participants about scientific facts and methods, particularly for robust STEM (science, technology, engineering, and math) learning. Two case studies illustrate the particularities of this specific collaboration or disciplinary appropriation for individual and community empowerment. 


\section{Art-based research for citizen science - an introduction}

Both citizen science (CS) and the arts can provide a path for collaborative research and learning - standing in the tradition of Mode 2 enabling research in the application context [1]. This sort of scientific and alternative knowledge production understands science outreach as variation of science communication. The terminology has shifted from 'public understanding' to 'public engagement', reflecting a model of communication that is contextual and participatory, and thus oriented to scientific citizenship and empowerment.

The current text follows the idea of cross-pollination between the arts and sciences for CS. Reflections of this sort have been institutionally highlighted for the first time in article 27 of the 1948 Universal Declaration of Human Rights (UDHR) establishing a broader human right to science and culture by highlighting "[...] the right to freely participate in the cultural life of the community, to enjoy the arts and to share in scientific advancement and its benefits." [2]

For CS strategies taken from the fields of artistic creation or art-based research may prove more effective regarding public engagement and transdisciplinary projects than those used by other academic approaches. They certainly challenge novel ways of thinking: "In the arts and humanities, the research approach, problem formulation and methods of data gathering and interpretation can differ from natural sciences, and it is important to acknowledge this variety. [...] Any research that is framed as citizen science is likely to be explicit about how it needs to be assessed as such [...] and should consider how participants are moving beyond being subjects of the research [...].” [3]

CS can involve dramatization, imagination, subjectivity-based critical encounters and public display; and can turn scientific knowledge and objective experiments into a shared experience and individual learning. When talking about science, the arts and blended forms of analyses, creation and communication labelled as SciArt have become increasingly popular. SciArt can encompass several artforms such as visual forms or it can take multi-modal or performative character. Although the term lacks a precise and widely accepted definition, one definition was suggested by collaborative artist Ann-Marie Atkinson: "[SciArt is] The post-disciplinary practice merging elements typically associated with The Arts and The Sciences which leads to an exploration in those areas." [4]

While science is related to objectivity, reliability and reproducibility, the arts can bring in messiness or amateurism mixing questioning scientific settings and key points which can lead to novel questions or approaches. Moreover, the arts can set the scene for "Probehandeln" (trial action) helping at group or individual level to research rather action-based and to learn experiencebased [5]. 
In this context, the arts can be categorized as three types of art and science engagements: (a) artists employing scientific processes to produce art - which can be found e.g. under the label 'BioArt'; (b) scientists and science communicators use art in science outreach; (c) artists and scientists exchange ideas, based on partnerships, to frame questions and explore the unknown [6].

Science outreach was described "as a framework that brings together scientific and nonscientific communities around a set of shared science outreach goals, which are met through the application of effective science communication, public engagement, and/or informal education best practices, and achieves outcomes characterized by mutual learning for all involved." [7]

Understanding science outreach as constituent element (and instrument) of CS involves the public as participants in real world experiments, in partnership with scientists or scientific organizations. CS projects often aim to educate their participants about scientific facts and methods, particularly by offering youth and educators unique opportunities to observe and explore the world through authentic research experiences that are necessary for robust STEM learning applying strategies and approaches of aesthetic or art-based research as inherent in for example BioArt or SciArt in general.

The following case studies describe the potential of CS at the intersection of art and science outreach showcasing the cooperation of scientific and artistic expertise or cultural intermediaries.

\subsection{Case Study 1: Learning microbiology by painting with microbes - NYC Biome MAP}

That art is a wonderful platform for science outreach is illustrated by the NYC Biome $M A P$, an "Agar Art" map of New York City (NYC) made by citizen scientists with glowing bacteria that was presented at the New Museum's Ideas City Festival in 2015. Drawing on notions of our personal microbiome and city's collective urban biome, the aim of the involved scientists and artists was to co-create an artwork that functions as an inclusive platform for the general public to learn about microbes. Project artistic staff fabricated stencils in shape of NYC's street grid, allowing the bacteria to grow in distinct patterns and forming the piece. The scientific staff oversaw laboratory logistics and led all hands-on activities, where citizen scientists learned how to handle and paint with microbes. The resulting artwork came in second in the inaugural American Society of Microbiology (ASM) International Agar Art contest and is still showcased widely, including the United Nations General Assembly 74 in New York. It inspired ASM in forming partnerships with community laboratories worldwide, with project staff consulting on quality criteria and a how-to guide published by ASM [8].

\subsection{Case Study 2: Knowledge production in galleries}

Literally experimental art challenges the viewer and in some cases even invites them to actively contribute to and participate in the showcased open-source experiments. For example, "Origins of Life Experiment \#1.2" by Adam Brown, a reinterpretation of the landmark MillerUrey experiment, first conducted in the 1950s. Interestingly the experiment has rarely been replicated, although science made significant progress in understanding the origin of life. This 
presented a unique opportunity to keep experimenting outside of the lab. Not only a gallery installation, it was also a fully functioning scientific experiment that allowed visiting citizen scientists to participate and contribute in generating novel data [9]. Brown writes about the project "Drawing the public into the process of experimentation forces each person to consider the meaning of origins for themselves, and asks them to question to what extent scientific knowledge can replace the origin myths it challenges." Similarly, data collected at two exhibitions at the Science Gallery Dublin and London resulted in scientific publications [10, 11].

\section{Call for action - \#Match4CitSciArt}

As exemplified, the collaboration between scientists, artists and communities can drive innovation in science and make research more accessible and meaningful to broad audiences. That's why we created a matchmaking Twitter hashtag to connect citizen scientists and artists. Get involved and use this hashtag to connect with other scientists, art educators and artists: \#Match4CitSciArt.

\section{References}

[1] M. Gibbons, H. Nowotny, C. Limoges, M. Trow, S. Schwartzman, P. Scott (1994). The New Production of Knowledge. The Dynamics of Sciences and Research in Contemporary Societies. p. 3 ff.

[2] United Nations (1948). The Universal Declaration of Human Rights. https://www.un.org/en/universal-declaration-human-rights/(retrieved 02/09/2020).

[3] ECSA (2020). European Citizen Science Association Working Paper. https://ecsa.citizenscience.net/wp-content/uploads/2020/05/ecsa_characteristics_of_citizen_science___v1_final.pdf (retrieved 10/07/2020).

[4] A.M Atkinson (2016). What is SciArt?. https://annemarieatkinson.co.uk/what-is-sciart/ (retrieved 07/06/2020).

[5] M. A. Wirtz (ed.) (2020) Dorsch. Lexikon der Psychologie. (keyword Probehandeln) https://dorsch.hogrefe.com/stichwort/probehandeln (retrieved 28/02/2021)

[6] S. Priyadarshini (2018). SciArt scribbles bringing art and science together for greater good. http://blogs.nature.com/indigenus/2018/12/sciart-scribbles-bringing-art-and-science-together-forgreater-good.html (retrieved 02/01/2021).

[7] J. Garbarino and SciOut18 Task Force (2019). Recommendations for the Continued Professionalization of Science Outreach within the Scientific Enterprise, in proceedings of SciOut18 conference https://rockedu.rockefeller.edu/new outreach/professionalization/ (retrieved $11 / 01 / 2021)$.

[8] American Society for Microbiology (2020). https://asm.org/Events/ASM-Agar-ArtContest/Previous-Winners (retrieved 11/01/2021).

[9] Adam Brown (2010) http://adamwbrown.net/projects-2/origins-of-life-experiment-1/ (retrieved $02 / 27 / 21)$

[10] D. O'Hora, R. Carey, A. Kervick, A. Crowley, M. Dabrowski (2016) Decisions in Motion: Decision Dynamics during Intertemporal Choice reflect Subjective Evaluation of Delayed Rewards. Sci. Rep. 6, 20740; doi: 10.1038/srep20740 
[11] D. O'Hora, S. Redfern, N. Duran, A. Zgonnikov and D. Sweeney (2018). In-Game Motion Dynamics Provide a Means of Exploring the Cognitive Dynamics of Deception, in proceedings of 2018 IEEE Games, Entertainment, Media Conference (GEM) DOI - 10.1109/GEM.2018.8516438 